\title{
IS TEACHING WITHOUT UNDERSTANDING CURRICULUM VISIONS AND GOALS A HIGH RISK?
}

\author{
S. B. Khoza \\ Discipline of Curriculum Studies and Educational Technology \\ University of KwaZulu-Natal \\ Durban, South Africa \\ e-mail: khozas@ukzn.ac.za
}

\section{ABSTRACT}

Subject/discipline curriculum/teaching vision is very important in teaching because it forms the foundation for why teachers teach their subjects. The vision is divided into personal daily experience, societal/social and professional/content visions/reasons. When teachers understand the teaching vision, they identify relevant curriculum goals. The goals are divided into aims, objectives and outcomes. Teachers have to understand the curriculum vision in order to achieve the curriculum goals. Therefore, this article presents an interpretive case study of two participants out of twenty university Bachelor of Education Honours students who specialised in Curriculum Studies. The purpose of the study was to explore the postgraduate students' understanding of curriculum visions and goals in teaching their subjects. These postgraduate students were full time teachers and part time students at a South African university. The postgraduate students' reflective journals, one-on-one semi-structured interview, lesson observation and focus group discussion were used for data generation. The study concluded that postgraduate students were not aware of the visions that underpin their teaching of the current South African curriculum. Although they were not aware of the visions, two participants were able to apply them in their teaching of the current South African curriculum. As a result of the application, they were able to interpret the curriculum. Participation in this study helped them to become aware of the importance of understanding visions, goals and critical reflections in order to apply these effectively. Purposive and convenience samplings were used to select the two most accessible participants from the twenty postgraduate students who participated in this study. This article consequently recommends the identification of visions that underpin the current curriculum, before teaching takes place, in order to identify measurable/observable goals and reflect on their teaching.

Keywords: Aims, discipline visions, objectives, outcomes, personal visions, social visions

\section{INTRODUCTION}

The teachers' lack of understanding of the curriculum/teaching visions (teaching rationale/reasons) and goals in teaching a curriculum is becoming a worldwide challenge that needs to be addressed in order to promote quality teaching and critical thinking (Berkvens, Van 
den Akker and Brugman 2014). As a result of the challenge, teachers continue to teach without identifying and understanding their subject/curriculum visions and relevant goals. The vision is very important because it is at the centre of any curriculum and it controls all curriculum concepts. Successful teachers in teaching start by identifying and understanding their curriculum vision followed by identifying relevant goals from their subject content (Khoza 2015c). Curriculum visions are divided into personal, societal, discipline/professional and reconstruction visions, while goals are divided into aims, objectives and outcomes. Understanding the curriculum visions help the teachers to reflect on their teaching in order to improve their teaching practice. Reflections as integral parts of quality teaching and critical thinking are divided into technical (discipline), practical (societal) and critical (personal) reflections (Van Manen 1977). This suggests a need for a study that explores the teachers' understanding of the curriculum visions and goals in order to understand which of these two has a major influence in motivating the teachers to teach their subjects. Once this is understood, critical reflection that promotes critical thinking (Foucault 2007), may be facilitated to assist teachers to always reflect on/in/for their teaching practices. Therefore, this study was conducted to explore the postgraduate students' understanding of visions and goals in order to contribute towards addressing this challenge. It is for this reason that the next section presents studies on understanding of curriculum definitions, visions and goals.

\section{LITERATURE: CURRICULUM/TEACHING VISION (RATIONALE/REASONS)}

According to Du Preez and Reddy $(2014,2)$ vision is a 'cognitive process that requires us to pull aside the curtains of habit, automatism, banality, so that alternative possibilities can be perceived'. This suggests that the reasons for designing, developing or teaching curriculum should not only be driven by everyday personal experience but should include societal, professional and/or reconstruction visions. However, curriculum visions may only be understood after the curriculum has been defined. As such, curriculum is defined as either a plan for teaching/learning (defined from the intended position - designers' level) (Berkvens, Van den Akker and Brugman 2014) or a plan of teaching/learning (defined from implemented/enacted or assessed position - teachers' or learners' experiences) (Pinar 2004). Curriculum may be represented by three main layers. The first layer (representation) is the intended, planned, prescribed, official or formal curriculum which is a written policy of ideas that are framed by educational vision with goal/s as well as the intentions of the teaching/learning curriculum (belongs to curriculum designers/developers). The second layer is implemented, enacted or practised curriculum, also known as curriculum in action (Khoza 
2015b), which is the interpretation of the intended curriculum as perceived by teachers and the actual process of teaching in operation (belongs to teachers). The third layer is the attained, achieved or assessed curriculum which is the learning experiences perceived by learners as measured through their achievement of learning outcomes (belongs to learners). Therefore, defining the curriculum from the first layer, the curriculum becomes the plan for teaching/learning and defining it from the second or third layer, it becomes the plan of teaching/learning. The curriculum or teaching vision which is divided into personal vision, societal/social vision and content (professional/discipline) vision is the central concept that controls all other curriculum concepts (Berkvens, Van den Akker and Brugman 2014). Over and above these three propositions of visions, Schiro (2013) identifies the forth one as the reconstruction vision.

Personal vision is the vision for teaching that puts individual teacher or learner at the centre of teaching/learning environment. This vision for teaching creates an environment that helps teachers and learners to construct their own unique individual identities (Khoza 2015a). When teachers create this supportive environment they include experiential and subjective activities that support the teachers and learners in order to construct and repeatedly reconstruct knowledge and, hence, take the form of personal meaning (identity). According to Schiro (2013) personal meanings make up the knowledge that is unique to each individual that possesses it; and holds personal significance to each person since the particular environmental context in which it is assimilated or constructed, is a result of experiences in a particular teaching/learning environment at a particular time. As a result, knowledge is viewed as a fundamental or basic part of learning because it is not a separate entity that has to be learned from outside the individual teacher or learner. Whatever is viewed as a teachers' or learners' habitual action helps them to understand themselves and also enables them to predict their societal responses as according to their stages of developments or experiences. The teachers' personal visions help them to choose whether they follow societal/social, professional/content or reconstruction (critical awareness) visions in their teaching. Therefore, personal visions become a foundation of societal, professional or reconstruction visions (rationale/reasons) and are determined by individual choice.

Societal/social vision places society at the centre of the teaching/learning environment. This teaching/learning environment is called competence/integrated/horizontal curriculum (Bernstein 1999). In competence curriculum, subjects are combined to form a learning area. For example, in South Africa during the time of the competence curriculum from 1997-2012, (Curriculum 2005 - C2005, Revised National Curriculum Statement - RNCS, National 
Curriculum Statement - NCS), Mathematics, Physical Science and Technology were combined into a single learning area. In South Africa, competence curriculum was driven by specified outcomes that were divided into seven critical outcomes, and five developmental and learning outcomes. Achievement of observable/measurable outcomes is the major practice in this type of curriculum or vision. Levels of outcomes (lower, middle or higher order) were not important, instead achievement of outcomes became an end to itself. As a result, learning was mostly influenced by opinions, local everyday or general knowledge and oral conversation. In this type of curriculum, knowledge is mostly generated horizontally from simple sources or local known sources. Assessment is mostly about what is present or what the learners (students) have achieved, not what the students should have achieved based on international standards (Khoza 2015c). In other words, students are sometimes compared to one another for achievement so that those who achieve more outcomes than others will be praised by society. In this type of curriculum vision, the vertical process of knowledge from lower level to higher level is not important because the vertical process is a function of professional/content (discipline) vision for teaching.

Professional (discipline/content) vision (rationale/reason) is a vision that places a discipline or profession at the centre of teaching/learning environment. This teaching vision is called performance/collection/vertical curriculum (Bernstein 1999) where cognitive domain is given more privilege than other domains. Cognitive domain is used to decide whether learners are successful or not within a specific discipline by mastering specific content. In performance curriculum each subject or discipline stands on its own and has its own collection of terminologies (concepts, theories, language, culture, ideologies and knowledge). It is driven by identified content where all students learn the same body of knowledge from the lowest to the highest levels. South Africa introduced the performance curriculum (Curriculum and Assessment Policy Statement - CAPS) in 2012 and each subject was given its own internationally identified content. The first group of learners who completed Grade 12 under this curriculum graduated in 2014. The pass rate of this group was lower than the previous groups which may suggest that the learners, teachers and/or the department of education did not understand the nature of performance curriculum as they were accustomed to the competence curriculum. In the performance curriculum recorded facts, school knowledge and international standards are used in making decisions. Students' performance is measured against international content standards. While performance curriculum may assess what students have learned, it mostly concentrates on what students should have achieved or learned. In other words, it looks for what is still cognitively missing because students are expected to 
learn from the lowest content (knowledge) to the highest content (knowledge) of the subject/discipline. Therefore, mastering the individual subject/discipline content is more important than the reconstruction of knowledge.

Reconstruction vision (rationale/reason) is also known as common collective vision (Schiro 2013) or critical reflective environment (Van Manen 1977). For this curriculum vision (rationale/reason) teachers use their conscious minds in their teaching in order to become aware of their actions at all times (all or nothing) and avoid the use of sub-conscious thoughts (habit without or limited thinking or awareness). The teachers have to constantly reflect on/in/for their practices in such a way that reflection becomes a result of their conscious mind (critical awareness of reflection), which may promote critical reflections that answer the questions of 'what', 'who', 'when', 'where', 'how' and 'why' within one’s teaching practice, discipline and society. According to Schiro (2013) reconstruction vision in teaching is used to eradicate social injustices in the prevailing culture and replace it with values and social practices that are more advantageous; it works towards reconstruction of a better culture in which all people achieve the maximum fulfilment of their spiritual, social, cultural, and professional or resource desires. For this curriculum or vision 'knowledge is not an impartial quantity and knowing is not a neutral affair', and as such, it should be interrogated because real knowledge supports the realisation of a better society, discipline and learners (Schiro 2013, 189). These curriculum visions are unpacked by teaching/learning goals.

\section{TEACHING GOALS}

According to Hyland, Kennedy, and Ryan (2006), as well as Khoza (2015b) goals are divided into aim, objective and outcome. While on the one hand, aim is a long term goal and objective is a short term goal, both indicate the teachers' intentions. On the other hand, outcome is what students should achieve at the end of a lesson or session. The outcomes are constructed according to specific observable/measurable keywords that reflect different levels of complexity as shown in Figure 1 (Bloom's taxonomies). The left hand side of Figure 1 indicates the original concepts of Bloom's taxonomies (teacher-centred approach) while the right hand side indicates the second version (learner-centred) of Bloom's taxonomies. Content-centred tends to be an intersection between the teacher-centred and learner-centred approaches where keywords that are used to generate learning outcomes arise. However, teaching/learning visions and goals, like any other curriculum concepts, are influenced by different ideological-ware (ideologies/theories) resources (Khoza 2015c) of which Bloom's taxonomy is one of the most dominating theories (especially in constructing the learning outcomes/assessment questions). 


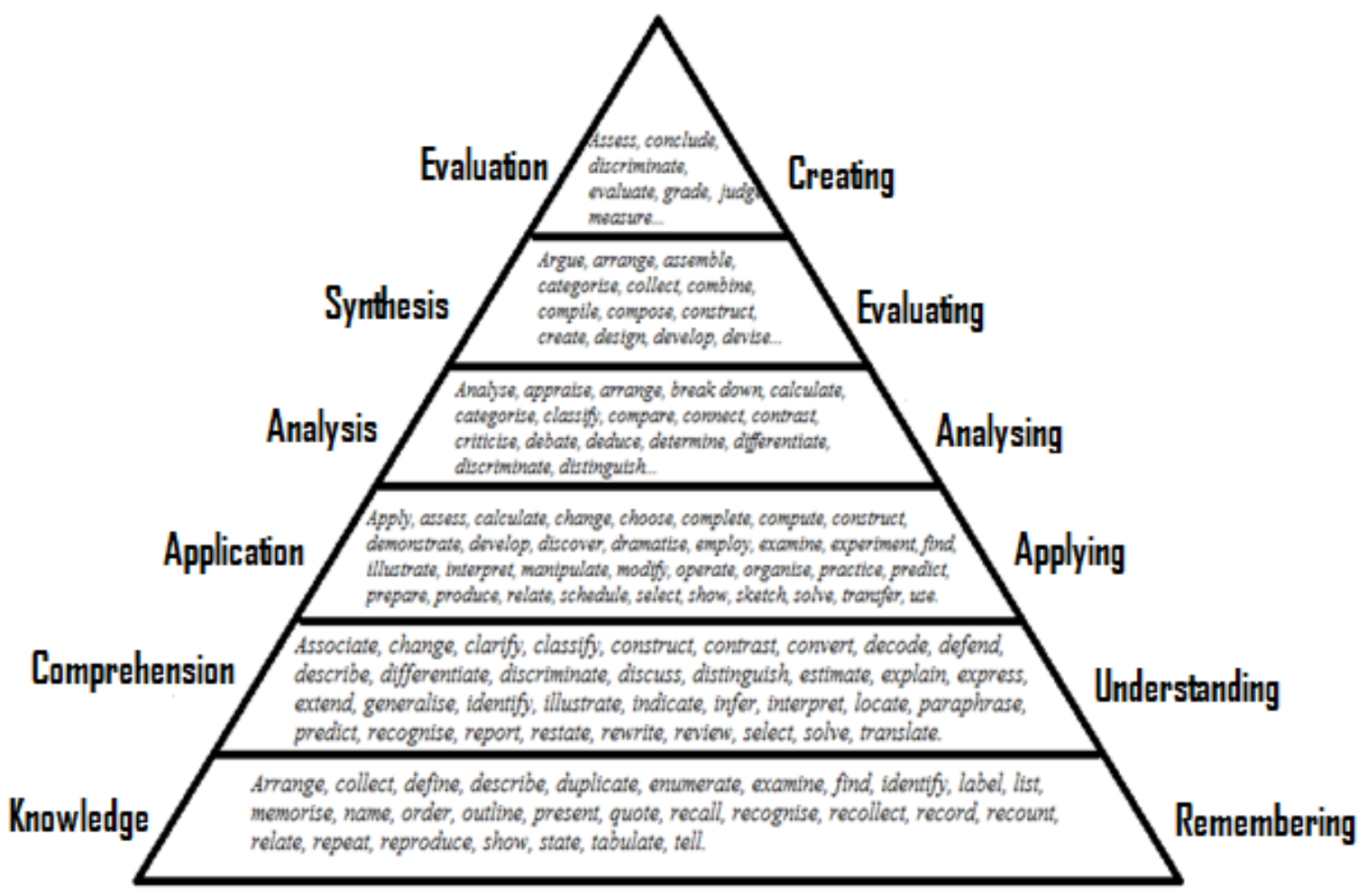

Figure 1: Benjamin Bloom Cognitive levels of outcomes and keywords

\section{RESEARCH AIMIOBJECTIVE AND RESEARCH QUESTIONS}

Therefore, this article intends to explore/understand teachers' understanding of the teaching/curriculum vision and goals. This article may help educational institutions to answer the question of 'why teachers understand teaching/curriculum visions and goals in particular ways?'

The data production was organised to respond to the following research questions:

- What are the teachers' understanding of the teaching/curriculum visions and goals at a South African university?

- Why do teachers understand teaching/curriculum visions and goals in particular ways?

\section{RESEARCH DESIGN AND METHODOLOGY}

This is an interpretive qualitative case study of two South African university Bachelor of Education Honours student teachers from the Curriculum Studies discipline. This study only reports on 2 participants from the 20 participants who undertook an Honours in Curriculum Studies. Qualitative case study is important for this study because it is more descriptive, holistic, explorative and contextual in its design and aims to produce rich description of explored phenomena (Creswell 2014). For this research, a qualitative case study has helped to establish 
the deeper meaning of the postgraduate students' understanding of the curriculum/teaching visions and goals because it is important at higher education level (Clare and Sivil 2014) as it promotes teaching awareness that brings about critical thinking (Khoza 2015c).

\section{SAMPLING}

Purposive sampling was used in selecting all 20 Bachelor of Education Honours postgraduate students from the university's Curriculum Studies. For this study, convenience sampling was then used to select the two participants who seemed to share a similar background. Although they have the similar background but their visions for/of teaching were not similar. It was interesting to observe that the other eighteen students whose findings were not reported here either followed Participant 1 or Participant 2 (both in other cases). The two postgraduate students were asked to answer the research questions through an email which was sent to all of them. The email included a reflective activity which helped them to write reflections on their understanding of teaching or curriculum visions and goals (based on their subjects). The reflective activity was followed by one-on-one semi-structured interviews and focus group semi-structured discussions. These students were the most accessible postgraduate students and both worked as full time teachers through the Department of Basic Education. This suggests that theoretical convenience sampling was also used to support the purposive sampling. As suggested by Krefting (1991), participants' names were not revealed because of ethical considerations. Informed consent and ethical clearance certificates were acquired from their department and university and confirmed their confidentiality, voluntary participation, benefit and anonymity from the university. However, this study will only report on Participant 1 and 2 because the space in the article is too limited to cover all twenty participants.

\section{DATA GENERATION/PRODUCTION AND ANALYSIS}

In order to answer the two research questions, research methods used for data generation included email with reflective activity, one-on-one semi-structured interview, lesson observation and semi-structured focus group discussion. The email with reflective activity was administered once and both the interviews and discussions were each administered twice and were about thirty minutes long. The lesson observation was done once for one hour per participant. The four sources of data generation were used for the purpose of authenticity of data and achieving measures of trustworthiness (Cohen, Manion and Morrison 2007). Audiotape was used to record the interviews for ease of transcription. This was done to verify that the data gathered was consistent across the three sources of data, that triangulation, transferability, 
dependability, confirmability and credibility were supported and to ensure trustworthiness of the findings.

In terms of data analysis this study used guided analysis (which produced narrative stories) where researchers have categories that can be modified through interaction with data (Khoza 2015a). The findings are exploratory in nature; two themes with categories were generated from the data as guided by the research questions. Six questions framed by the six propositions (personal, societal/social, professional/content, aims, objectives and outcomes) of the two main study concepts (vision and goals) were used in the three data generation methods. These framed questions that helped to answer the two research questions which guided the presentation and discussion of findings. The themes and categories were used for both narrative presentation of the findings and the discussion of findings.

\section{FINDINGS}

Narrative stories (mostly by means of direct quotations from the activity reflection and interviews to answer the research questions and to ensure trustworthiness) are used to present the findings from the two themes (visions and goals) with four categories. The narrative stories exclude the citations (references) that were included by Participant 1 in her reflective activities. Even during the interviews, Participant 1 cited different scholars who informed her practice. The citations/references are represented by three full stops (...). After the presentation of the findings (narrative stories), four discussion themes were generated in order to substantiate the findings with discussions and re-contextualise them with relevant literature. Both these participants were involved in the Mathematics curriculum but their teaching reasons/visions were not the same (although they have the same background).

\section{Participant 1}

Both my parents are teachers but they are not giving anything away without working hard for it. They are demanding more information from us about anything we want to achieve in life. So, we grew up reading different sources in order to get facts about anything we wanted to achieve ...

As a mathematics teacher, I try to expose my learners to real world mathematics, by practical experiences, as often as possible because I believe that the skills and knowledge acquired from maths has real life applications. For instance, a learner cannot learn the concept of measuring mass by listening to the teacher's explanations, but rather, the learner must physically pick up a variety of objects to discover the concept of light and heavy. I feel that learners exist in a world full of mathematical concepts, like shapes and patterns, and therefore learners have every reason to engage with this real life knowledge. For this reason, I perceive or view mathematical knowledge as empirically constructed ideas and concepts from evidence in the real world. ... explains that 'perceptions of the nature and role of mathematics held by our society have a major influence on the development of school mathematics curriculum, instruction, and research'. Therefore, my 
perception of mathematical knowledge may influence how my learners view and respond to the subject and ultimately the curriculum ... Society places great value on mathematics education and I hope that my learners will use their acquired mathematical skills and knowledge to break free from the poverty cycle and open new doors of opportunity... it is worth noting that the ideas shaped by the mathematics CAPS ...

From the rationale for teaching, we can derive and identify the aims and objectives for/of learning. ... looks at the goals that one should work toward after the rationales have been identified. It is necessary to draw a distinction between aims, objectives and outcomes so that designers, implementers and recipients of the curriculum recognise their goals and take ownership of their stance - and in doing so, the implementation process of the curriculum can be a fruitful one.

... indicate that 'the aim of a module or programme is a broad general statement of teaching intention, i.e. it indicates what the teacher intends to cover in a block of learning'. While ... refers to the concept of aims as 'intended outcomes'.... According to the CAPS document, the aims for teaching are stated as 'general aims' ... It is worth noting that the general aims are not necessarily specific to mathematics teaching, but the objectives indicated by the CAPS document are more relevant to mathematics. ... define objectives as 'a specific statement of teaching intention'. While ... refers to the notion of objectives as implemented outcomes ... According to the CAPS document, objectives are labelled as 'specific aims'...... it is important to distinguish the goals of the learner and for this reason, learning outcomes ... as 'statements of what a learner is expected to know, understand and/or be able to demonstrate after completion of a process of learning'... In terms of CAPS, learning outcomes are presented as 'specific skills' while the concept of Bloom's taxonomy is represented within assessment ...

\section{Participant 2}

My parents are strict in demanding us to follow their instructions without questioning them. They are both teachers ... I am teaching Mathematics with optimum passion and interest and able to instil the similar aspect to the learners, as a result there are enjoying learning the subject and always admire it as a human creation. Using the approach as suggested by the Department of Education using the Curriculum and Assessment Policy Statement of Mathematics which advocates that all learners shall be taught the importance of learning the subject regardless of gender or socio economic background.

I give all learners fair and equal opportunities in learning the subject by following my instructions. This has increased the morale in my learners in wanting to know more and doing Mathematics as a subject and learn to respect. Not only has this resulted in my learners to achieve better marks in their learning but also enabled them to enroll at various institutions in seeing the need to continue with related careers involving Mathematics such as Engineering and Information Technology. However I view content as integral system of the subject. It becomes the core in focusing on what relevant topics should be taught to the learners and with application.

I do and continuously plan before each lesson, for each topic as to which aim will the lesson be directed and what learners will achieve as specific skills. I have noted progress in leaners cognitive levels through this method. However I do view this aspect of the curriculum to be carefully studied and applied, so as to select appropriate aims. Nonetheless, the Curriculum and Assessment Policy Statement succeeds this vital aspect of what the Curriculum should entail in its focus of Aims. ... having an aim and an objective becomes more precise on what you will attain after. This is set with an understanding of having a purpose ...

Sometimes I feel like am trapped in the teaching profession where I am sustaining my parents legacy and wish to see myself running a big business that turns me into a millionaire ... 


\section{DISCUSSION OF FINDINGS}

The findings confirm the existence of the four curriculum or teaching visions/reasons as discussed above. But the two participants perceive these visions in different ways even though they taught the same subjects. This suggests that their home environment influenced them differently although they went to the same high school for their secondary education. It was interesting to note that they went to the same university (in 2010), they undertook Honours together and were employed at the same school. The findings generated four visions for teaching mathematics curriculum with relevant goals as: Personal (everyday identity experience) vision from Aims, Social vision from Outcomes, Discipline vision from Objectives and Critical Awareness vision from Aims, Objectives and Outcomes (as themes).

\section{PERSONAL (EVERYDAY IDENTITY EXPERIENCE) VISION FROM AIMS}

The findings suggest that the participants' teaching visions (rationale/reasons) were generated from the parents' aims (long term goals) of helping them to find their personal identities. Finding their personal everyday identities helped them to know/understand their teaching strengths and weaknesses. When they did their everyday activities, they automatically reflected their personal identities which were achieved through their everyday activities under their parents' aims (supervision). Parents had aims (long term goals) about the future of these two participants. The aims were translated into the new participants' finding personal/self-identities. As a result, they used the personal identities (visions) to develop or align themselves with certain curriculum or teaching visions. The curriculum or teaching/learning visions are sometimes referred to as Foucault's 'technologies of self' because they internally help teachers to manage their activities/actions (Davids 2013). Other scholars use different concepts such as ideological-ware (Khoza 2015a), ideology (Amory 2012) and technology of education or underware (Percival and Ellington 1988) to represent the visions as the most important curriculum/teaching resource that we cannot see and touch but still controls our teaching/actions. Perhaps the personal visions may be understood as teachers' internal theories that tell the teachers what to do or not to do in their teaching.

Parents seem to have an important role to play in helping children to find their identity/self, which in turn translates into one or more of the curriculum/teaching/learning visions. For example, Participant 1 developed a culture of reading because she was challenged by her parents (get information about her activities). Her parents' main aim was to develop a culture of reading because they believed that 'instilling the culture of reading and studying is the only 
way to help their children to open all the existing doors of information to get knowledge about everything because knowledge is power ...'. By so doing the parents helped her to develop research knowledge/skills of searching relevant information, reading and using the information in her teaching/learning environment. As a result, her teaching was found to be driven by personal vision (it helps her learners to find their personal visions), social vision (helps her learners to develop knowledge/skills required by their communities), discipline vision (helps her learners to read studies on Mathematics) and critical awareness vision (helps her learners to be critically aware of activities that built their future).

On the other hand, Participant 2 was found to be a very strict teacher whose Mathematics instructions were followed by almost all his learners. This suggests that his teaching was driven by personal and discipline visions. He had never practised teaching according to the social vision because he was not prepared 'to allow learners to deviate from the given instructions because learners do not learn to respect adult people if they are given a room not to follow Mathematics instructions ...'. As a result, he always worked as an instructor, which started to weigh on him and could have led to his wish to have his own business. Having his own business may suggest that he was trying to distance himself from his parents' culture which promoted elements of the teacher-centred or/and content-centred approach and which favour the discipline/professional/content vision. Therefore, he may have been influenced by other teachers who enjoyed teaching because of social vision because 'these teachers have more time to socialise while we are always serious ... so I do wish to taste what they do ...'. This suggests that he was bored by discipline vision and wished to learn an unfamiliar vision (social) to him.

\section{SOCIAL VISION FROM OUTCOMES}

Participant 1 used observable/measurable learning outcomes to drive her other lessons. She used the keywords from Bloom's taxonomies (Figure 1) according to the six levels of cognitive domain to generate learning outcomes and assessment questions. From her reading she was aware that the South African curriculum (CAPS) was not driven by the learning outcomes but the content and kept the lessons that were driven by the learning outcomes to a minimal. Both these participants were aware that the outcomes in CAPS were represented by specific skills. However, Participant 1 had to revise some of these specific skills/outcomes because they were not observable and had objective keywords instead of outcome keywords (Khoza 2015b). She was able to justify the reasons of keeping some elements of the competence curriculum (social vision) even if South Africa had introduced the performance curriculum (discipline vision). She decided to keep the elements of competence curriculum (social vision) because '... the subject 
has real life applications. For instance, a learner cannot learn the concept of measuring mass by listening to the teacher's explanations, but rather, the learner must physically.... Society places great value on mathematics education and I hope that my learners will use their acquired mathematical skills and knowledge to break free from the poverty cycle and open new doors of opportunity ....' This suggests that, while she wanted to keep her learners at the centre of her teaching environment she also wanted to keep the community at the centre of her teaching environment. Therefore, the findings suggest that using observable/measurable learning outcomes to drive lessons help learners to develop knowledge and skills according to the needs of the learners' communities. However, Participant 2 was not interested in the competence curriculum because he felt that to 'practice the competence curriculum while South Africa implements CAPS [performance curriculum - discipline vision] is a sign of disrespect'. However, he acknowledged that 'sometimes it is tempting to follow other teachers if they work against CAPS ...'. This suggests that his teaching was framed by CAPS and other teaching rules (discipline/content/professional vision). These are qualities of discipline vision (performance/vertical curriculum) and technical reflection (Van Manen 1995). Therefore, this confirms that Participant 2's teaching vision was discipline (content/professional) vision.

\section{DISCIPLINE VISION FROM OBJECTIVES}

Both these participants used content to generate their lesson objectives in different ways over and above the CAPS objectives. Although they both used Curriculum and Assessment Policy Statement (CAPS), which is a performance curriculum (discipline vision), their teaching was not the same. For example, Participant 2's teaching privileged the content (mastering Mathematics content), specific skills (represent outcomes) and cognitive levels (taken from formal assessment) over any other curriculum concepts. These are qualities of performance/collection/vertical curriculum which are in line with CAPS (Khoza 2015c). However, Participant 2 only followed the specified curriculum and prescribed Mathematics resources (including books). His personal vision limited him under the concept of 'respect' which was sewn into him by his parents. Although his vision was mostly directed toward formal instruction, he included well thought out activities that needed to be measured with objectives (short term goals). He was well organised with all relevant resources (Ngubane-Mokiwa and Khoza 2016) that were planned for his learners. He was able to push his learners to achieve higher marks that were based on the lesson objective (specific aims). He was aware that outcomes (specific skills) are achieved by the learners (belong to learners) and decided to 'use objectives because they are achieved by teachers (belong to teachers) in order to make sure that 
learners focus according to the given instructions ...'. This suggests that his learners may only learn effectively if the vision for learning is discipline/content/professional vision (performance curriculum).

On the other hand, Participant 1 included other lessons that were also taught according to the performance curriculum because she was aware that she had to 'follow CAPS as the South African curriculum ... I use facts from the book about CAPS to promote content with teachercentred approach and oral general ideas from other people to promote learner-centred approach.' She was able to effectively mix the discipline vision through performance curriculum with societal vision through competence curriculum to create a good teaching and learning environment that produced learning signals (Khoza 2015c). Learning signal is any concept of curriculum that promote teaching/learning environment such as visions, goals, assessment, content, learning activities, resources, teacher role, type of learners, learning platform and time. These learning signals require this teaching and learning environment in order to support the teacher and learners to effectively teach and learn respectively (Herrington, Reeves and Oliver 2004). According to Herrington, Reeves and Oliver (2004, 55) this teaching and learning environment is important because it uses authentic activities that 'are ill-defined [unstructured], requiring students to define the tasks and sub-tasks needed to complete the activity'. This suggests that Participant 1's learners may be able to learn in many different environments because they may be able to define and structure their own tasks.

\section{CRITICAL AWARENESS VISION FROM AIMS, OBJECTIVES AND OUTCOMES}

The reconstruction vision can be simplified as critical awareness vision because it involves reflection on (past or after teaching/action), in (present or during teaching/action) and for (future or before teaching/action) one's teaching practice. According to Van Manen (1995) teacher reflection is divided into technical, practical and critical reflections. The technical reflection level takes place when teachers reflect in order to develop knowledge and skills that help them to maintain order needed to achieve educational aims (Van Manen 1977). This suggests that Participant 2's teaching incorporated this kind of reflection because his teaching was technically controlled by instructions shaped by his concern that he achieved his teaching objectives. This is in line with performance curriculum.

Practical reflection is where teachers are worried about applying what they learned at training institutions to their classroom situations which can sometimes further frustrate them if they do not understand all the curriculum concepts (learning signals). Critical reflection is where teachers practise deep reflections by reflecting on both power relations and activities that 
seem to be important in the present situation but could become problematic in future (Adler 1991). In order for one to apply critical reflection for critical thinking one has to go through extensive reading and collaboration with other scholars in one's discipline/subject (Van Manen 1995). '... I always share Mathematics readings with other specialists in the field in order to understand Mathematics reasons and aims with objectives as well as relevant outcomes for my learners ...' (Participant 1). Therefore, this suggests that Participant 1 was able to apply the visions by linking the goals and reflections as effective taxonomies of teaching and learning that helped her and her learners to deal with the ill-defined tasks (Herrington, Reeves and Oliver 2004)

\section{CONCLUSION WITH EDUCATIONAL IMPLICATIONS}

The findings conclude that it is important for the teachers to understand the teaching visions, goals and reflections in order to liberate themselves through their teaching environments. However, too much application of discipline vision (performance curriculum) without other visions, promotes a too strict teaching/learning environment (Khoza and Manik 2015) that turned Participant 2's teaching environment into a programmed robotically system or conveyerbelt that advocated for behaviourist ideologies (Monahan 2004) or surveillance and automation (Rizvi and Lingard 2010). In order to avoid this too strict environment, teachers should teach in such a way that they perceive alternative possibilities (Du Preez and Reddy 2014), meaning that they should reflect on/in/for their teaching in order to understand the visions, goals and other teaching/learning signals (Khoza 2015c).

On the other hand, Participant 1's findings seem to demonstrate how teachers can overcome the teaching challenges (limited understanding of the curriculum visions, goals and other learning signals) that undermine their teaching environments. Her personal vision provided her with the culture of reading and searching for relevant information (reading relevant sources). The personal vision (self-identity shaped by family experience/culture) built a strong foundation for social vision (society/community identity/culture shaped by knowledge requisition or informal learning). The social vision built a strong foundation for discipline vision (formal teaching and learning shaped by school knowledge). A combination of personal vision, social vision, discipline vision and goals (aims, objectives and outcomes) produced a strong foundation of reconstruction or critical awareness vision (see Participant 1's account). Participant 1 used these visions and goals as taxonomies of teaching and learning according to their strength. Although she used these visions and goals without being aware of them, she did begin to understand her teaching environment through her involvement in this study. The same 
goes for Participant 2 who started to understand his teaching practice through his participation in this study. Both the participants highly recommended that all teachers should be encouraged to critically reflect (critical awareness vision) on their teaching practice in order to interrogate their past (correct/sustain where necessary), present and predict their future teaching methods. However, critical reflection has to start with the culture of reading for relevant information and make space for other learning signals thereafter.

Therefore, understanding the visions, goals and reflections may help the teachers to overcome the temptations to do what they are not supposed to do in their teaching (by imitating others without understanding the visions and goals). The temptations may work against the discipline vision if they are not informed by research/studies. However, this can be avoided if teachers understand the visions, goals, critical reflections and other learning signals.

\section{ACKNOWLEDGEMENT}

This project was sponsored by UKZN Teaching \& Learning Office (UTLO).

\section{REFERENCES}

Adler, A. 1991. The reflective of teacher and the curriculum of teacher education. Journal of Education for Teaching 17(2): 139-150.

Amory, A. 2012. Tool-mediated authentic learning in an educational technology course: A designedbased innovation. Interactive Learning Environments (ahead-of-print):1-17.

Berkvens, J., J. van den Akker and M. Brugman. 2014. Edited by Addressing the quality challenge: Reflections on the Post-2015 UNESCO Education Agenda. England: Netherlands National Commission for UNESCO.

Bernstein, B. 1999. Vertical and horizontal discourse: An essay. British Journal of Sociology of Education 20(2): 157-173.

Clare, J. and R. Sivil. 2014. Autonomy lost: The bureacratisation of South African higher education. South African Journal of Higher Education 28(1): 60-71.

Cohen, L., C. Manion and K. Morrison. 2007. Research methods in education. 6th ed. New York: Routledge.

Creswell, J. W. 2014. Qualitative inquiry and research design: Choosing among five approaches. 3rd ed. California: SAGE Publications, inc.

Davids, M. N. 2013. Can Foucault come to the rescue? From dogma to discourse: Deconstructing the history of education for democratic subjects. Yesteday \& Today 9(2013): 108-124.

Du Preez, P. and C. Reddy. 2014. Curriculum studies: Visions and imaginings. Cape Town: Peason Holdings Southern Africa (Pty) LTD: Liesbet van Wyk.

Foucault, M. 2007. Security, territory, population: Lectures at the Collége de France 1977-1978. New York: Picador.

Herrington, J., T. C. Reeves and R. Oliver. 2004. A development research agenda for online collaborative learning. Educational Technology Research and Development 52(4): 53-65.

Hyland, A., D. Kennedy and N. Ryan. 2006. Writing and using learning outcomes: A practical guide. Bologna: European Higher Education Area (EHEA). 
Khoza, S. B. 2015a. Can Turnitin come to the rescue: From teachers' reflections? South African Journal of Education 35(4) :1-9.

Khoza, S. B. 2015b. Student teachers' reflections on their practices of Curriculum and Assessment Policy Statement. South African Journal of Higher Education 29(4): 179-197.

Khoza, S. B. 2015c. Using curricular spider web to explore a research facilitator's and students' experiences. South African Journal of Higher Education 29(2): 122-143.

Khoza, S. B. and S. Manik. 2015. The recognition of 'digital technology refugees' amongst post graduate students in a Higher Education institution. Alternation 17(2015): 190-208.

Krefting, L. 1991. Rigor in qualitative research: The assessment of trustworthiness. The American Journal of Occupational Therapy 45(3): 214-222.

Monahan, T. 2004. Just another tool? IT pedagogy and the commidification of education. The Urban Review 36(4): 271-292.

Ngubane-Mokiwa, S. A. and S. B. Khoza. 2016. Lecturers' experiences of teaching STEM to students with disabilities. Journal of Learning for Development - JL4D 3(1): 37-50.

Percival, F. and H. Ellington. 1988. A handbook of educational technology. 2nd ed. London: Kogen Page.

Pinar, W. F. 2004. What is curriculum theory? Mahwah, N.J: Lawrence Erlbaum and Assoc.

Rizvi, F. and B. Lingard. 2010. Globalizing education policy. New York: Routledge.

Schiro, M. S. 2013. Curriculum theory: Conflicting visions and enduring concerns. 2nd ed. Thousand Oaks: Sage.

Van Manen, M. 1977. Linking ways of knowing with ways of being practical. Curriculum Inquiry 6(1977): 205-212.

Van Manen, M. 1995. On the epistemology of reflective practice. Teachers and Teaching: Theory and practice 1(1): 33-50. 